\title{
MODEL REGRESI NONPARAMETRIK SPLINE TRUNCATED PADA JUMLAH KASUS TUBERKULOSIS DI PROVINSI BALI TAHUN 2016
}

\author{
Ni Putu Rina Anggreni ${ }^{1 \S}$, Ni Luh Putu Suciptawati ${ }^{2}$, I Gusti Ayu Made Srinadi ${ }^{3}$
}

\begin{abstract}
${ }^{1}$ Program Studi Matematika, Fakultas MIPA - Universitas Udayana [Email: rinaanggreni592@gmail.com]
${ }^{2}$ Program Studi Matematika, Fakultas MIPA - Universitas Udayana [Email: suciptawati@unud.ac.id]

${ }^{3}$ Program Studi Matematika, Fakultas MIPA - Universitas Udayana [Email: srinadi@unud.ac.id]
\end{abstract}

\begin{abstract}
Tuberculosis is a contagious disease caused by Mycobacterium tuberculosis. Based on data from the health office of Bali Province, in 2015 tuberculosis cases found 0,96\%, while in 2016 tuberculosis cases increase to 1,05\%. This research used truncated spline nonparametric regression to model tuberculosis cases in Bali Province in 2016. This method was used because truncated spline has high flexibility compared to other polynomial models. The truncated spline function has a connecting point called knots. The best estimation of truncated spline regression model is obtained from optimal knot point selection by calculating minimum generalized cross validation. The estimated truncated model is linear with one knot point with determination coefficient equals to 70,48 \%. In addition, it is also found in order to reduce tuberculosis cases the government of Bali Province should increase percentage of family who lives clean and healthy.
\end{abstract}

Keywords: Bali, Generalized Cross Validation (GCV), Knots, Tuberculosis, Truncated Spline.

\section{PENDAHULUAN}

Tuberkulosis merupakan penyakit menular yang disebabkan oleh bakteri berbentuk batang (basil) yang bernama Mycobacterium Tuberculosis. Penyakit ini dapat menular secara langsung melalui udara dalam bentuk percikan dahak (droplet nuclei). Penyakit tuberkulosis masih menjadi masalah kesehatan di beberapa negara, salah satunya negara Indonesia.

Menurut Kementerian Kesehatan RI (2016), jumlah kasus tuberkulosis di Indonesia ditemukan sebanyak 298.128 kasus. Pada tahun 2015, jumlah kasus tuberkulosis ditemukan sebanyak 0,96\% di Provinsi Bali (Dinas Kesehatan, 2016). Selain itu, pada tahun 2016 ditemukan sebanyak 1,05\% (Dinas Kesehatan, 2016). Menyikapi kasus tuberkulosis yang semakin meningkat di Provinsi Bali, maka berbagai cara telah dilakukan oleh pemerintah Provinsi untuk me-nurunkan jumlah kasus tuberkulosis. Salah satu caranya yaitu melakukan analisis untuk mengetahui faktor- faktor yang memengaruhi jumlah kasus tuberkulosis.

Penelitian mengenai faktor-faktor yang memengaruhi jumlah kasus tuberkulosis telah dilakukan oleh beberapa peneliti. Lestari dkk (2014) melakukan analisis mengenai faktorfaktor yang memengaruhi jumlah kasus tuberkulosis di Jawa Timur dengan metode Geographically Weighted Poisson Regression (GWPR) dan Generalized Poisson Regression (GPR). Nisa dan Budiantara (2016) melakukan analisis mengenai faktor-faktor yang memengaruhi jumlah kasus tuberkulosis di Jawa Timur menggunakan metode regresi spline, dengan memberikan saran kepada peneliti selanjutnya agar melakukan penambahan variabel yaitu kepadatan penduduk dan pengembangan menggunakan empat titik knot.

Pendekatan regresi spline merupakan salah satu estimator pada pendekatan regresi nonparametrik, yang digunakan untuk melakukan estimasi terhadap kurva regresi karena bentuk kurva regresi diasumsikan smooth (mulus). 
Pendekatan regresi spline memiliki suatu basis fungsi, basis fungsi yang biasa digunakan antara lain spline truncated dan B-spline (Lyche, 2008). Truncated merupakan fungsi yang dapat diartikan sebagai fungsi potongan. Oleh karena itu, spline truncated merupakan model polinomial yang memiliki sifat terpotongpotong. Memiliki sifat terpotong-potong tersebut, maka spline memiliki fleksibilitas yang lebih tinggi di-bandingkan dengan model polinomial biasa sehingga dapat menyesuaikan diri secara lebih efektif terhadap karakteristik lokal suatu fungsi data, dengan kata lain spline dapat menghasilkan fungsi regresi yang sesuai dengan data.

Dalam fungsi spline terdapat titik-titik penghubung yang disebut titik knot. Titik knot merupakan titik fokus dalam fungsi spline sehingga kurva yang dibentuk dapat terbagi pada titik tersebut. Akibatnya secara visual dapat menggambarkan secara jelas perubahan perilaku-perilaku dari model spline pada interval-interval yang berbeda, sebagai ciri khas pendekatan spline. Berdasarkan uraian diatas maka peneliti ingin mengetahui bagaimana model regresi non-parametrik spline truncated pada jumlah kasus tuberkulosis di Provinsi Bali pada tahun 2016.

\section{KAJIAN PUSTAKA}

Regresi spline merupakan model polinomial tersegmen yang mulus. Dalam fungsi spline terdapat titik-titik penghubung yang disebut titik knot. Secara umum model regresi nonparametrik spline truncated pada suatu fungsi dengan orde $m$ untuk satu variabel respon dan satu variabel prediktor dapat dinyatakan sebagai berikut (Eubank R. L., 1999):

$$
\begin{aligned}
Y_{i}= & \sum_{r=0}^{m-1} \alpha_{r} t_{i}{ }^{r}+\sum_{p=1}^{l} \alpha_{(m-1+p)}\left(t_{i}-k_{p}\right)_{+}^{m-1} \\
& +\varepsilon_{i} ; \quad i=1,2,3, \ldots, n .
\end{aligned}
$$

dengan $\alpha_{0}, \alpha_{1}, \alpha_{2}, \ldots, \alpha_{(m-1)}, \alpha_{(m-1+p)}$ merupakan parameter koefisien regresi, $t_{i}{ }^{1}, t_{i}{ }^{2}, \ldots$ ,$t_{i}{ }^{m-1}$ merupakan satu variabel prediktor yang nilainya diketahui, dan $\left(t_{i}-k_{p}\right)_{+}^{m-1}$ merupakan fungsi truncated yang dapat diuraikan sebagai berikut:

$$
\left(t_{i}-k_{p}\right)_{+}^{m-1}=\left\{\begin{array}{ll}
\left(t_{i}-k_{p}\right)^{m-1}, t_{i} \geq k_{p} \\
0, & t_{i}<k_{p}
\end{array} .\right.
$$

Estimasi parameter $\alpha$ pada regresi nonparametrik spline truncated dapat dilakukan dengan metode maximum likelihood estimator (MLE). Jika galat pada persamaan (1) diasumsikan berdistribusi normal, maka $Y_{i}$ juga berdistribusi normal, in-dependen dengan nilai tengah $f\left(t_{i}\right)$ dan varians-nya $\sigma^{2}$. Dengan demikian, fungsi densitas peluang $Y_{i}$ menjadi:

$f\left(Y ; f(t), \sigma^{2}\right)=\frac{1}{\sqrt{2 \pi \sigma^{2}}} \exp \left[-\frac{(Y-f(t))^{2}}{2 \sigma^{2}}\right]$.

dengan $f(t)>0, \sigma^{2}>0$

Fungsi likelihood dapat dinyatakan sebagai berikut:

$$
\begin{gathered}
L(Y, f)=\left(2 \pi \sigma^{2}\right)^{-\frac{n}{2}} \exp \left[-\frac{1}{2 \sigma^{2}} \sum_{i=1}^{n}\left(Y_{i}-\right.\right. \\
\left.\left.f\left(t_{i}\right)\right)^{2}\right] .
\end{gathered}
$$

Estimator titik $f$ diperoleh dengan memaksimumkan fungsi likelihood $L(Y, f)$ yang dapat dinyatakan sebagai berikut:

$$
\begin{gathered}
\max \{L(Y, f)\}=\max _{\alpha \in R^{m+r}}\left\{( 2 \pi \sigma ^ { 2 } ) ^ { - \frac { n } { 2 } } \operatorname { e x p } \left[-\frac{1}{2 \sigma^{2}}\right.\right. \\
\sum_{i=1}^{n}\left(Y_{i}-\left(\sum_{r=0}^{m-1} \alpha_{r} t_{i}{ }^{r}+\right.\right. \\
\left.\left.\left.\left.\sum_{p=1}^{l} \alpha_{(m-1+p)}\left(t_{i}-k_{p}\right)_{+}^{m-1}\right)\right)^{2}\right]\right\} .(5)
\end{gathered}
$$

Selanjutnya, apabila persamaan (5) dilanjutkan sampai selesai maka diperoleh estimator $\alpha$ sebagai berikut:

$$
\hat{\alpha}=\left(t^{\prime} t\right)^{-1} t^{\prime} Y
$$

Sehingga, estimasi dari $\hat{Y}$ dapat diuraikan sebagai berikut:

$$
\widehat{Y}=t\left(t^{\prime} t\right)^{-1} t^{\prime} Y=A(k) Y .
$$

Untuk menentukan model regresi spline dapat menggunakan metode GCV. Nilai GCV minimum merupakan model terbaik dengan titik knot yang optimal. Fungsi GCV didefinisikan sebagai berikut (Eubank R. L., 1999):

$$
G C V(k)=\frac{\operatorname{MSE}(k)}{\left(n^{-1} \operatorname{tr}[I-A(k)]\right)^{2}} .
$$

dengan $\quad \operatorname{MSE}(k)=n^{-1} \sum_{i=1}^{n}\left(Y_{i}-\hat{Y}\right)^{2}$, $\widehat{Y}=t\left(t^{\prime} t\right)^{-1} t^{\prime} Y, I$ merupakan matriks identitas, $n$ merupakan banyaknya data, $k$ merupakan banyaknya titik knot $\left(k_{1}, k_{2}, k_{3}, \ldots, k_{p}\right)$ dan $A(k)=t\left(t^{\prime} t\right)^{-1} t^{\prime}$. 


\section{METODE PENELITIAN}

Data yang digunakan dalam penelitian ini adalah data sekunder yang diperoleh dari Dinas Kesehatan Provinsi Bali tahun 2016 dan Badan Pusat Statistika (BPS) Provinsi Bali tahun 2017. Data sekunder yang digunakan berupa jumlah kasus tuberkulosis pada 57 kecamatan di Provinsi Bali tahun 2016.

Variabel respon yang digunakan pada penelitian ini adalah jumlah kasus tuberkulosis pada 57 kecamatan di Provinsi Bali tahun 2016 $(Y)$ dan persentase rumah tangga ber-PHBS $\left(X_{1}\right)$, persentase kepadatan penduduk $\left(X_{2}\right)$, persentase tempat umum sehat $\left(X_{3}\right)$, persentase pengelolaa makanan sehat $\left(X_{4}\right)$, persentase usia produktif $\left(X_{5}\right)$, dan tenaga kesehatan terlatih $\left(X_{6}\right)$ merupakan variabel prediktor.

Teknik analisis data dilakukan dengan regresi nonparametrik spline truncated dan bantuan Program R 3.3.2. Langkah-langkah analisis data yang dilakukan sebagai berikut:

1. Menyajikan statistika deskripsi variabel respon dan variabel prediktor.

2. Memilih titik knot optimal dengan menggunakan GCV yang paling minimum dengan tahapan sebagai berikut:

a. Mencari matriks $A(k)$ yang memenuhi persamaan (7).

b. Mencari nilai Mean Square Error (MSE).

c. Mencari titik knot optimal dengan menggunakan nilai GCV yang sesuai dengan persamaan (8).

3. Memodelkan variabel respon dan variabel prediktor dengan regresi non-parametrik spline truncated dengan titik knot optimal.

4. Menghitung nilai koefisien determinasi $\left(R^{2}\right)$.

5. Menginterpretasikan model yang didapatkan dari regresi nonparametrik spline truncated.

\section{HASIL DAN PEMBAHASAN}

Gambaran umum dari jumlah kasus tuberkulosis dengan persentase rumah tangga ber-PHBS, persentase kepadatan penduduk, persentase tempat umum sehat, persentase pengelolaan makanan sehat, persentase usia produktif, dan presentase tenaga kesehatan terlatih.
Tabel 1. Statistika deskripsi faktor-faktor yang diduga berpengaruh.

\begin{tabular}{|c|r|r|r|c|}
\hline \multirow{2}{*}{ Variabel } & \multicolumn{4}{|c|}{ Statistika Deskripsi } \\
\cline { 2 - 5 } & Min & Max & Mean & $\begin{array}{c}\text { Simpangan } \\
\text { Baku }\end{array}$ \\
\hline $\mathrm{Y}$ & 4 & 117 & 34,16 & 29,64 \\
\hline $\mathrm{X}_{1}$ & 39,5 & 100 & 76,10 & 11,32 \\
\hline $\mathrm{X}_{2}$ & 0,2 & 13,4 & 1,760 & 2,475 \\
\hline $\mathrm{X}_{3}$ & 57,1 & 100 & 94,386 & 6,993 \\
\hline $\mathrm{X}_{4}$ & 0 & 100 & 50,57 & 35,25 \\
\hline $\mathrm{X}_{5}$ & 59,1 & 76 & 67,633 & 2,740 \\
\hline $\mathrm{X}_{6}$ & 41,40 & 97,20 & 85,64 & 9,01 \\
\hline
\end{tabular}

Berdasarkan Tabel 1 dapat dilihat bahwa jumlah kasus tuberkulosis terendah ditemukan sebanyak 4 kasus. Menurut Suarni (2009) dalam skripsi (Fitri, 2017), faktor yang memengaruhi jumlah kasus tuberkulosis adalah faktor karakteristik individu dan faktor lingkungan. Salah satu faktor lingkungan yang memengaruhi jum-lah kasus tuberkulosis adalah suhu. Menurut Gould dan Brooker (2003), bakteri Mycobacterium Tuberculosis dapat tumbuh optimal pada suhu $33^{\circ} \mathrm{C}-37^{\circ} \mathrm{C}$. Berdasarkan data Dinas Ke-sehatan Provinsi Bali tahun 2016, dilihat bahwa Kecamatan Payangan memiliki suhu udara rata-rata mencapai $26^{\circ} \mathrm{C}$ dengan suhu minimum rata-rata $23^{\circ} \mathrm{C}$ dan suhu maksimum rata-rata $29^{\circ} \mathrm{C}$. Hal ini menyebabkan bakteri Mycobacterium Tuberculosis tidak dapat tumbuh dengan optimal di Kecamatan Payangan. Oleh karena itu, ditemukan jumlah kasus tuberkulosis terendah di Kecamatan Payangan.

Berbeda dengan Kecamatan Payangan, Kecamatan Denpasar Utara memiliki suhu maksimum berkisar antara $29,9^{\circ} \mathrm{C}-33,9^{\circ} \mathrm{C}$ dan suhu minimum berkisar antara $22,7^{\circ} \mathrm{C}-25,6^{\circ} \mathrm{C}$ yang menyebabkan bakteri Mycobacterium Tuberculosis dapat tumbuh secara optimal. Oleh karena itu, banyak masyarakat di Kecamatan Denpasar Utara yang terkena bakteri tuberkulosis. Hal ini menyebabkan Kecamatan Denpasar Utara menempati peringkat tertinggi dengan jumlah kasus tuberkulosis terbanyak yaitu 117 kasus. Ditemukan persentase rumah tangga ber-PHBS terendah sebesar 39,5\% dan tertinggi sebesar $100 \%$. Berdasarkan data Dinas 
Kesehatan Provinsi Bali tahun 2016, dapat dilihat bahwa persentase rumah tangga berPHBS terendah terjadi di Kecamatan Baturiti dan tertinggi terjadi di Kecamatan Ubud. Hal ini menyebabkan Kecamatan Ubud telah memenuhi standar rumah tangga ber-PHBS dari Dinas Kesehatan Provinsi Bali. Menurut Dinas Kesehatan Provinsi Bali, rumah tangga berPHBS merupakan seluruh anggota keluarga berperilaku hidup bersih dan sehat yang memenuhi sepuluh indikator yaitu pertolongan persalinan oleh tenaga kesehatan, bayi diberi ASI eksklusif, balita ditimbang setiap bulan, menggunakan air bersih, mencuci tangan dengan air bersih dan sabun, menggunakan jamban sehat, memberantas jentik di rumah sekali seminggu, makan sayur dan buah setiap hari, melakukan aktivitas fisik setiap hari, dan tidak merokok di dalam rumah.

Ditemukan persentase kepadatan penduduk terendah sebesar $0,2 \%$ dan tertinggi sebesar 13,4\%. Diperoleh dari data Dinas Kesehatan Provinsi Bali tahun 2016, persentase kepadatan penduduk terendah terjadi di Kecamatan Selemadeg dan tertinggi terjadi di Kecamatan Denpasar Barat. Ditemukan persentase tempat umum sehat terendah sebesar $57,1 \%$ dan tertinggi sebesar $100 \%$. Berdasarkan data Dinas Kesehatan Provinsi Bali tahun 2016, dapat dilihat bahwa persentase tempat umum sehat terendah terjadi di Kecamatan Selat dan Karangasem. Persentase tempat umum sehat tertinggi terjadi di 15 kecamatan yaitu Kecamatan Susut, Melaya, Negara, Pekutatan, Banjarangkan, Klungkung, Dawan, Sideman, Tabanan, Selemadeg, Selemadeg Barat, Selemadeg Timur, Pupuan, Marga dan Kediri. Hal ini menunjukkan, 15 kecamatan tersebut telah memenuhi kriteria sarana sehat dari Dinas Kesehatan Provinsi Bali.

Berdasarkan tabel 1, dapat dilihat bahwa persentase tempat pengelolaan makanan sehat terendah sebesar 0 dan tertinggi sebesar $100 \%$. Dilihat dari data Dinas Kesehatan Provinsi Bali tahun 2016, ditemukan persentase tempat pengelolaan makanan sehat terendah terjadi di Kecamatan Dawan karena tempat pengelolaan makanan di Kecamatan Dawan tidak memenuhi persyaratan higiene sanitasi yang sesuai dengan standar Dinas Kesehatan Provinsi Bali. Berbeda dengan Kecamatan Dawan, Kecamatan Selemadeg Barat dan Kuta memiliki persentase tempat pengelolaan makanan sehat tertinggi. Hal ini menunjukkan bahwa tempat pengelolaan makanan di Kecamatan Selemadeg Barat dan Kuta telah memenuhi persyaratan higiene sanitasi yang sesuai dengan standar Dinas Kesehatan Provinsi Bali. Persentase usia produktif terendah sebesar $59,1 \%$ dan tertinggi sebesar 76\%. Diperoleh dari data Dinas Kesehatan Provinsi Bali tahun 2016, persentase usia produktif terendah terjadi di Kecamatan Kubu dan tertinggi terjadi di Kecamatan Kuta. Selain itu, ditemukan persentase tenaga kesehatan terlatih terendah sebesar 41,40\% dan tertinggi sebesar 97,2\%. Berdasarkan data Dinas Kesehatan Provinsi Bali tahun 2016, dilihat bahwa persentase tenaga kesehatan terlatih terendah ditemukan di Kecamatan Nusa Penida. Hal ini disebabkan kurang-nya tenaga kesehatan terlatih seperti dokter umum, dokter spesialis, dokter gigi, dokter gigi spesialis, bidan, perawat, dan apoteker.

Tabel 2. Nilai GCV Minimum, Titik Knot Optimal, dan Orde Optimal

\begin{tabular}{|c|c|c|}
\hline $\begin{array}{l}\text { Banyaknya } \\
\text { Titik Knot }\end{array}$ & Orde & GCV \\
\hline 1 & \multirow{5}{*}{2} & 427,743 \\
\hline 2 & & 428,405 \\
\hline 3 & & 513,069 \\
\hline 4 & & 587,347 \\
\hline 5 & & 662,305 \\
\hline 1 & \multirow{5}{*}{3} & 524,57 \\
\hline 2 & & 651,84 \\
\hline 3 & & 673,73 \\
\hline 4 & & 766,56 \\
\hline 5 & & 1663,8 \\
\hline 1 & \multirow{5}{*}{4} & 12172 \\
\hline 2 & & 207940 \\
\hline 3 & & 2644650 \\
\hline 4 & & 1551712 \\
\hline 5 & & 2534240 \\
\hline
\end{tabular}

Untuk menentukan model regresi nonparametrik spline truncated terbaik dapat 
menggunakan metode GCV. Nilai GCV minimum merupakan model terbaik dengan titik knot yang optimal. Selanjutnya diuraikan pemilihan titik knot pada masing-masing orde seperti tabel 2.

Berdasarkan Tabel 2, menunjukkan bahwa nilai GCV minimum diperoleh pada regresi nonparametrik spline truncated linear (orde 2) dengan satu titik knot. Titik-titik knot optimal berturut-turut terletak pada titik $X_{1}=82$; $X_{2}=1,64 ; \quad X_{3}=95,3 ; X_{4}=76,4 ; X_{5}=69,1$ dan $X_{6}=90$ dengan nilai GCV sebesar 427,74. Dengan demikian, diperoleh estimasi model terbaik yaitu model regresi nonparametrik spline truncated linear (orde 2) dengan satu titik knot yang dapat dinyatakan sebagai berikut:

dengan

$$
\begin{aligned}
\hat{Y}_{i}= & \hat{\alpha}_{0}+\hat{\alpha}_{1} X_{1}+\hat{\alpha}_{2} \beta_{1}+\hat{\alpha}_{3} X_{2}+\hat{\alpha}_{4} \beta_{2} \\
& +\hat{\alpha}_{5} X_{3}+\hat{\alpha}_{6} \beta_{3}+\hat{\alpha}_{7} X_{4}+\hat{\alpha}_{8} \beta_{4} \\
& +\hat{\alpha}_{9} X_{5}+\hat{\alpha}_{10} \beta_{5}+\hat{\alpha}_{11} X_{6}+\hat{\alpha}_{12} \beta_{6} .
\end{aligned}
$$

$$
\begin{aligned}
& \beta_{1}= \begin{cases}\left(X_{1}-82\right) & , X_{1} \geq 82 \\
0, & X_{1}<82\end{cases} \\
& \beta_{2}= \begin{cases}\left(X_{2}-1,64\right) & , X_{2} \geq 1,64 \\
0, & X_{2}<1,64\end{cases} \\
& \beta_{3}=\left\{\begin{array}{ll}
\left(X_{3}-95,3\right) & , X_{3} \geq 95,3
\end{array} .\right. \\
& \beta_{4}= \begin{cases}\left(X_{4}-76,4\right) & X_{3}<95,3 \\
0, & X_{4} \geq 76,4\end{cases} \\
& \beta_{5}= \begin{cases}\left(X_{5}-69,1\right) & , X_{5} \geq 69,1 \\
0, & X_{5}<69,1\end{cases} \\
& \beta_{6}= \begin{cases}\left(X_{6}-90\right) & X_{6} \geq 90 \\
0, & X_{6}<90\end{cases}
\end{aligned}
$$

dan estimasi parameter disajikan dalam Tabel 3.

Tabel 3. Estimasi Parameter Model Regresi Non-parametrik Spline Truncated

\begin{tabular}{|c|r|}
\hline Parameter & \multicolumn{1}{|c|}{ Estimasi } \\
\hline$\alpha_{0}$ & 215,350 \\
\hline$\alpha_{1}$ & 0,09234 \\
\hline$\alpha_{2}$ & $-1,83861$ \\
\hline$\alpha_{3}$ & 21,8074 \\
\hline$\alpha_{4}$ & $-15,6092$ \\
\hline$\alpha_{5}$ & $-0,10625$ \\
\hline$\alpha_{6}$ & $-0,76369$ \\
\hline$\alpha_{7}$ & 0,49096 \\
\hline$\alpha_{8}$ & $-1,09198$ \\
\hline$\alpha_{9}$ & $-2,9434$ \\
\hline$\alpha_{10}$ & 8,40687 \\
\hline$\alpha_{11}$ & $-0,30386$ \\
\hline$\alpha_{12}$ & $-2,15071$ \\
\hline
\end{tabular}

dengan demikian, estimasi model yang diperoleh adalah sebagai berikut :

$$
\begin{aligned}
\hat{Y}_{i}= & 215,35010+0,09233931 X_{1}-1,83861 \beta_{1} \\
& +21,80736 X_{2}-15,6092 \beta_{2}-0,10625 X_{3} \\
& -0,76369 \beta_{3}+0,490958 X_{4}-1,09198 \beta_{4} \\
& -2,9434 X_{5}+8,406869 \beta_{5}-0,30386 X_{6} \\
& -2,15071 \beta_{6} .
\end{aligned}
$$

dengan nilai GCV sebesar 427,74 dan koefisien determinasi $R^{2}=0,70$. Hal ini menunjukkan bahwa model jumlah kasus tuberkulosis pada kecamatan $\mathrm{ke}-i$ di Provinsi Bali dengan menggunakan regresi nonparametrik spline truncated dengan variabel persentase rumah tangga ber-PHBS, persentase kepadatan penduduk, per-sentase tempat umum sehat, persentase tempat pengelolaan makanan sehat, persentase usia produktif dan persentase tenaga kesehatan terlatih mampu menerangkan 70,48\% keragaman jumlah kasus tuberkulosis pada kecamatan ke- $i$ di Provinsi Bali tahun 2016. Sisanya $29,52 \%$ di-pengaruhi oleh variabel lain di luar model ataupun galat.

Berikut ini merupakan interpretasi fungsi truncated untuk masing-masing $X_{1}, X_{2}, X_{3}, X_{4}$, $X_{5}, X_{6}$ pada model regresi nonparametrik spline truncated linear (orde 2) dengan satu titik knot dapat diuraikan sebagai berikut:

1. Jika variabel $X_{2}, X_{3}, X_{4}, X_{5}, X_{6}$ sama dengan nilai rata-ratanya, maka persentase rumah tangga ber-PHBS $\left(X_{1}\right)$ terhadap jumlah kasus tuberkulosis pada kecamatan ke $-i$ di Provinsi Bali $\left(Y_{i}\right)$ adalah sebagai berikut:

$\widehat{Y}_{i}=41,5636+0,092339 X_{1}-1,83861 \beta_{1} \cdot(9)$

Ketika persentase rumah tangga berPHBS pada kecamatan $\mathrm{ke}-i$ di Provinsi Bali bernilai maksimum yaitu $100 \%$, maka nilai maksimum tersebut disubstitusikan ke persamaan (9). Dengan demikian ditemukan jumlah kasus tuberkulosis pada kecamatan tersebut sebanyak 18 kasus. Selain itu, ketika persentase rumah tangga ber-PHBS pada kecamatan ke- $i$ di Provinsi Bali ber-nilai minimum yaitu $39,5 \%$, maka nilai minimum tersebut juga disubstitusi ke persamaan (9). Dengan demikian, 
ditemukan jumlah kasus tuberkulosis pada keca-matan tersebut sebanyak 45 kasus. Oleh karena itu, ketika persentase rumah tangga ber-PHBS meningkat, maka akan me-nurunkan jumlah kasus tuberkulosis di Provinsi Bali.

Menurut Dinas Kesehatan Provinsi Bali Rumah tangga ber-PHBS merupakan upaya untuk memberdayakan anggota rumah tangga agar tahu, mau, dan mampu mempraktikan perilaku hidup bersih dan sehat serta berperan aktif dalam gerakan kesehatan di masyarakat. Untuk mencapai rumah tangga ber-PBHS harus memenuhi sepuluh indikator yaitu pertolongan persalinan oleh tenaga kesehatan, bayi diberi ASI eksklusif, balita ditimbang setiap bulan, menggunakan air bersih, mencuci tangan dengan air bersih dan sabun, menggunakan jamban sehat, memberantas jentik di rumah sekali se-minggu, makan sayur dan buah setiap hari, melakukan aktivitas fisik setiap hari, dan tidak merokok di dalam rumah.

2. Jika variabel $X_{1}, X_{3}, X_{4}, X_{5}, X_{6}$ sama dengan nilai rata-ratanya, maka persentase kepadatan penduduk $\left(X_{2}\right)$ terhadap jumlah kasus tuberkulosis pada kecamatan $\mathrm{ke}-i$ di Provinsi Bali $\left(Y_{i}\right)$ adalah sebagai berikut:

$\widehat{Y}_{i}=12,083+21,80736 X_{2}-15,609 \beta_{2} \cdot(10)$

Ketika persentase kepadatan penduduk pada kecamatan ke- $i$ di Provinsi Bali bernilai maksimum yaitu $13,4 \%$, maka jumlah kasus tuberkulosis pada kecamatan tersebut ditemukan sebanyak 316 kasus. Selain itu, ketika persentase kepadatan penduduk pada kecamatan ke $-i$ di Provinsi Bali bernilai minimum yaitu $0,2 \%$ maka jumlah kasus tuberkulosis pada kecamatan tersebut ditemukan sebanyak 16 kasus. Dengan demikian, ketika persentase kepadatan penduduk meningkat, maka akan meningkatkan jumlah kasus tuberkulosis di Provinsi Bali. Kepadatan penduduk merupakan jumlah penduduk disuatu wilayah per-km².
3. Jika variabel $X_{1}, X_{2}, X_{4}, X_{5}, X_{6}$ sama dengan nilai rata-ratanya, maka persentase tempat umum sehat $\left(X_{3}\right)$ terhadap jumlah kasus tuberkulosis pada kecamatan ke- $i$ di Provinsi Bali $\left(Y_{i}\right)$ adalah sebagai berikut: $\hat{Y}_{i}=58,62-0,10625 X_{3}-0,76369 \beta_{3}$. (11)

Ketika persentase tempat umum sehat pada kecamatan ke- $i$ di Provinsi Bali bernilai maksimum yaitu $100 \%$, maka jumlah kasus tuberkulosis pada kecamatan tersebut ditemukan sebanyak 44 kasus. Selain itu, ketika persentase tempat umum sehat pada kecamatan ke $-i$ di Provinsi Bali bernilai minimum yaitu $57,1 \%$, maka jumlah kasus tuberkulosis pada kecamatan tersebut ditemukan sebanyak 53 kasus. Dengan demikian, ketika persentase tempat umum sehat meningkat, maka akan menurunkan jumlah kasus tuberkulosis di Provinsi Bali.

Tempat-tempat umum merupakan tempat/sarana yang diselenggarakan pemerintah atau swasta atau perorangan yang digunakan untuk kegiatan bagi masyarakat yang meliputi sarana kesehatan (rumah sakit, pus-kesmas), sarana sekolah (SD, SMP, SMA), dan hotel. Untuk mencapai tempat umum sehat maka harus memenuhi kriteria sarana sehat dari Dinas Kesehatan Provinsi Bali.

4. Jika variabel $X_{1}, X_{2}, X_{3}, X_{5}, X_{6}$ sama dengan nilai rata-ratanya, maka persentase tempat pengelolaan makanan sehat $\left(X_{4}\right)$ terhadap jumlah kasus tuberkulosis pada kecamatan ke $-i$ di Provinsi Bali $\left(Y_{i}\right)$ adalah sebagai berikut:

$\widehat{Y}_{i}=24,76+0,490958 X_{4}-1,09198 \beta_{4} \cdot(12)$

Ketika persentase tempat pengelolaan makanan sehat pada kecamatan $\mathrm{ke}-i$ di Provinsi Bali bernilai maksimum yaitu $100 \%$, maka jumlah kasus tuberkulosis pada kecamatan tersebut ditemukan sebanyak 24 kasus. Selain itu, ketika persentase tempat pengelolaan makanan sehat pada kecamatan ke- $i$ di Provinsi Bali bernilai minimum yaitu 0 , maka jumlah kasus tuberkulosis pada kecamatan tersebut 
ditemukan sebanyak 25 kasus. Dengan demikian, ketika persentase tempat pengelolaan makanan sehat meningkat, maka akan menurunkan jumlah kasus tuberkulosis di Provinsi Bali.

Tempat pengelolaan makanan merupakan usaha pengelolaan makanan yang meliputi jasa boga atau catering, rumah makan dan restoran, depot air minum, kantin dan makanan jajanan. Untuk mencapai tempat pengelolaan makanan sehat harus memenuhi persyaratan higiene sanitasi yang sesuai dari Dinas Kesehatan Provinsi Bali.

5. Jika variabel $X_{1}, X_{2}, X_{3}, X_{4}, X_{6}$ sama dengan nilai rata-ratanya, maka persentase usia produktif $\left(X_{5}\right)$ terhadap jumlah kasus tuber-kulosis pada kecamatan $\mathrm{ke}-i$ di Provinsi Bali $\left(Y_{i}\right)$ adalah sebagai berikut:

$\widehat{Y}_{i}=247,661-2,9434 X_{5}+8,40687 \beta_{5} .(13)$

Ketika persentase usia produktif pada kecamatan $\mathrm{ke}-i$ di Provinsi Bali bernilai maksimum yaitu $76 \%$, maka jumlah kasus tuberkulosis pada kecamatan tersebut ditemukan sebanyak 82 kasus. Selain itu, ketika persentase usia produktif pada kecamatan $\mathrm{ke}-i$ di Provinsi Bali bernilai minimum yaitu $59,1 \%$, maka jumlah kasus tuberkulosis pada kecamatan tersebut ditemukan sebanyak 74 kasus. Dengan demi-kian, ketika persentase usia produktif menurun, maka akan menurunkan jumlah kasus tuberkulosis di Provinsi Bali. Menurut Dinas Kesehatan Provinsi Bali, usia produktif yaitu usia 15-64 tahun.

6. Jika variabel $X_{1}, X_{2}, X_{3}, X_{4}, X_{5}$ sama dengan nilai rata-ratanya, maka persentase tenaga kesehatan terlatih $\left(X_{6}\right)$ terhadap juml-ah kasus tuberkulosis pada kecamatan ke $-i$ di Provinsi Bali $\left(Y_{i}\right)$ adalah sebagai berikut:

$\widehat{Y}_{i}=74,613-0,30386 X_{6}-2,15071 \beta_{6} \cdot(14)$

Ketika persentase tenaga kesehatan terlatih pada kecamatan ke- $i$ di Provinsi Bali bernilai maksimum yaitu $97,2 \%$, maka jumlah kasus tuberkulosis pada kecamatan tersebut ditemukan sebanyak 45 kasus.
Selain itu, ketika persentase tenaga kesehatan terlatih pada kecamatan $\mathrm{ke}-i$ di Provinsi Bali bernilai minimum yaitu 41,4\%, maka jumlah kasus tuberkulosis pada kecamatan tersebut ditemukan sebanyak 62 kasus.

\section{SIMPULAN DAN SARAN}

Berdasarkan interpretasi dari model regresi nonparametrik spline truncated linear (orde 2), diperoleh bahwa ketika persentase rumah tangga ber-PHBS pada kecamatan ke $-i$ di Provinsi Bali bernilai maksimum yaitu 100, maka jumlah kasus tuberkulosis pada kecamatan tersebut ditemukan sebanyak 18 kasus. Selain itu, untuk persentase kepadatan penduduk, persentase tempat umum sehat, persentase pengelolaan makanan sehat, persentase usia produktif dan persentase tenaga kesehatan terlatih diperoleh jumlah kasus tuberkulosis lebih banyak dari 18 kasus. Dengan demikian, sebaiknya pemerintah Provinsi Bali meningkatkan persentase rumah tangga ber-PHBS guna menurunkan jumlah kasus tuberkulosis di Provinsi Bali.

Dalam penelitian ini hanya menggunakan spline truncated untuk memodelkan jumlah kasus tuberkulosis di Provinsi Bali tahun 2016. Di-harapkan penelitian selanjutnya melakukan per-bandingan menggunakan basis fungsi spline yang lainnya seperti $B$-spline.

\section{DAFTAR PUSTAKA}

BPS. (2017). Provinsi Bali Dalam Angka 2017. Denpasar: BPS Provinsi Bali

Dinas Kesehatan. (2015). Profil Kesehatan Provinsi Bali. Denpasar: Dinas Kesehatan Provinsi Bali

(2016). Profil Kesehatan Provinsi Bali. Denpasar: Dinas Kesehatan Provinsi Bali.

Eubank, R. L. (1999). Nonparametric Regression and Spline Smoothing (2nd ed.). New York: Marcel Dekker.

Fitri, E. U. (2017). "Pemodelan Faktor-faktor 
Yang Memengaruhi Jumlah Kasus Tuberkulosis di Jawa Timur Menggunakan Metode Geographically Weighted Generalized Poisson Regression dan Geographically Weighted Negative Binomial Regression". Skripsi. Institut Teknologi Sepuluh Nopember.

Gould, D.,\& Brooker, C., (2003). Mikrobiologi Terapan untuk Perawat. Jakarta: EGC.

Kementerian Kesehatan RI. (2016). Data dan Informasi Profil Kesehatan Indonesia. Jakarta: Kementrian Kesehatan RI.

Lestari, R. D., Wulandari, S. P., \& Purhadi. (2014). Pemodelan Faktor-Faktor yang Memengaruhi Jumlah Kasus Penyakit Tuberkulosis di Jawa Timur dengan Pendekatan Generalized Poisson Regression dan Geographically Weighted Poisson Regression. Jurnal Sains dan Seni Pomits Vol.3.No.2, 2337-3539.

Lyche, T. (2008). Spline Methods. Department of Informatics Centre of Mathematics for Application University of Olso .

Nisa', F. F., \& Budiantara, I. N. (2016). Pemodelan Faktor-faktor yang Memengaruhi Jumlah Kasus Tuberkulosis di Jawa Timur Menggunakan Regresi Non-parametrik Spline. Jurnal Sains dan Seni Pomits Vol.5.No.2, 2337-3520. 